\title{
Building the Core Concepts for Biology Teaching in the Middle School
}

\author{
Bi-ying Yao \\ School of Environmental and Life Sciences \\ Guangxi Teachers Education University \\ Nanning 530001, China \\ Rong He \\ School of Environmental and Life Sciences \\ Guangxi Teachers Education University \\ Nanning 530001, China
}

\author{
Zhong-hua Zhang \\ School of Environmental and Life Sciences \\ Guangxi Teachers Education University \\ Nanning 530001, China \\ Ya Wen \\ School of Environmental and Life Sciences \\ Guangxi Teachers Education University \\ Nanning 530001, China
}

\author{
Gang $\mathrm{Hu}^{*}$ \\ School of Environmental and Life Sciences \\ Guangxi Teachers Education University \\ Nanning 530001, China \\ ahhugang@gmail.com
}

\begin{abstract}
The core concepts of the biology are in the center of the knowledge of the discipline. It reflects the features of the knowledge of the discipline and contains the rich discipline ideas and methods. The core concept teaching approach mostly consisting of the exploring ways is encouraged in the current education in China. This paper suggests biology teachers in the middle school should explore to promote an effective teaching strategy built by the core concepts so as to help the students master and apply the core concepts to solve the real problems.
\end{abstract} school

Keywords-teaching strategy; core concept; biology; middle

\section{INTRODUCTION}

The core concepts are the important knowledge of the discipline and play the key role. It is in the dominant position and can lead the general concepts [1]. The core concepts can lead and guide the contents of the chapters and play the role of bringing up the essential points. The relevant concepts should be combed before class and the key of organizing effectively the teaching is identifying the position of the core concepts in the biology. The core concepts can reflect the contents of the discipline and contain the discipline ideas and methods. There are many abstract and indigestible concepts in the teaching of biology, such as enzyme, DNA, etc. When the teachers organize the class teaching, they should excavate fully the discipline ideas and methods containing in the concepts and enable the students participate positively the process of solving the problems and master the thought way of the exploration. The teaching organized around the core concepts is a very effective way of teaching activities. So, the biology teachers in the middle school need to organize purposely the teaching activities centering on the core concepts [2].
The improvement of the teaching level of the core concepts of biology is not only the fundamental guarantee of improving the teaching quality of biology but also the only road of the professional development of the biology teachers. More importantly, it is the key which improve the scientific cultivation of biology of the students. In the traditional "Duckstuffing" type of teaching, the teachers always inculcate the basic concepts in the students and ignore the original living experiences, knowledge background and the existence of prescientific concepts of the students, and also ignore that the learning of the students is a process of building positively. The problem about how to precede an effective teaching around the core concepts of biology has already been the problem that all of the biology teachers are facing. The author of the article provided several suggestions regarding how to promote the building of the core concepts of biology for the hope of improving the teaching level of biology in the high schools.

\section{Teaching StRategy OF PROMOting the BUILDING OF THE CORE CONCEPTS OF BIOLOGY}

\section{A. Refine and Identify the Core Concepts}

For the teaching contents of a lesson, if it is short of a core concept or idea, it will be undoubtedly dull and boring. For example, in the teaching of the subject of "gene mutation and gene recombination" in the high school, if the teachers only list the knowledge of textbooks according to the contents of the teaching materials and haven't any core concept leading the theme of the chapter, it will be unmeaningful for the students to understand and build the concepts. The teachers should take the "variation" as the core concept and start with the examples in the living of the students and ask the students summarize the types of the variation of the genes themselves. Then, there is a 
"soul" and idea in the knowledge when coming to the gene mutation and gene recombination. Finally, the teachers summarize the nature, characteristics and the reasons of the gene mutation and the types \& meaning of the gene recombination. As a core concept, the "variation" leads the relevant knowledge of this lesson and highlights the key of the class teaching, and more importantly, it embodies its value in the biology. Thus, in the class teaching, listing the detailed facts from the life of the students and then summarizing the detailed facts and refining the core concepts in the process of forming the knowledge is one of the effective strategies of promoting the building of the concepts in the students.

\section{B. Analyze the Core Concepts with Multiple Perspectives}

The achieving of the concepts doesn't mean the understanding of the concepts. The intention of the concepts is much more rich and profound than the meaning of the concepts the teachers need to analyze the core concepts with multiple perspectives and master the intention and the extension of the core concepts [3]. The intention and the extension of the concepts are consolidated in the same concept and both of them can't exist separately. They are always related closely and they interact each other. For example, the intention of "gene mutation" is the variation of the structure of the genes and the standard attribute of the gene mutation is the increasing, shortage and change of the base pairs happening in the DNA molecules. Its extension includes the features of the gene mutation, the factors leading to the mutation and the application of the artificial mutation in the breeding. The intention of the same concept of "meiosis" is the specialty of the meiosis, and the extension is the relation between the meiosis and the gametogenesis, the role of the meiosis in the life circle, and the relation between the meiosis and the genetic variation. Thus, the establishment of the core concept is achieved by the analysis of multiple perspectives with the strict thinking method.

\section{Bind the General Concepts and the Detailed Concepts}

Binding the general concepts, detailed concepts and the core concepts in the teaching materials is the key of the teaching of the core concepts [4]. For example, in the teaching of the chapter of "chromosome variation", there are many concerning concepts such as Chromosome variation, deletion, duplication, inversion, translocation, chromosome group, haploid, diploid, and polyploidy etc. These fragmentary concepts are very abstract. If the teachers don't comb the logic relations among all of the concepts, it is possible that the students will confuse easily about these concepts. So, the teachers create the concept map according to the upper and lower relation of the concepts for helping the students summarize and build the knowledge frame.

The process of summarizing the knowledge is the process of building knowledge systems in the brains of the students. Comparing to the concepts teaching of simple repetition, building the logic relations between the concepts by applying the concept map can be better for rediscovering the changes and developments of the things with the mutual relations and unity of the concepts. Moreover, the drawing of the concept map can not only help effectively the teachers clarify the teaching contents and master the core concepts for enabling the teachers achieve a purposed teaching in the teaching process, but also promote the students to master the concepts and build the knowledge networks [5]. The application of the drawing of the concept map, the constructing of the visible thinking support and the displaying of the thinking process of the students can improve the cognitive level of the students for the core concepts.

\section{Enrich the detailed examples of the concepts}

1) Create the Life Situation and Search the Classic Examples

The teachers need to excavate fully the life of the students, create the life situation and search the classic examples such as the "Updated Development Zones" of the students for building the concepts of biology. The developments of the students are achieved in the real life and the education needs to focus more on the real life activities and the demands of the students. The real life is the main force source that the students get the reliable developments and the life examples are the strong lever for the students to learn the concepts. For example, when learning the triploid seedless watermelon in the "chromosome variation", the teachers can create the situations starting from the examples in the life of the students. For example, before learning the contents of the chapter of "examples of material transport across membranes", the teachers can provide the following questions to the students: Why the phenomenon of "burn seedings" happens when overfertilizing the crops? Why the wilted vegetables on the market will become liven after being sprinkled with water? The thinking is developed based on the original life experiences of the students and it fits for the cognitive features of the students so that it can inspire the intrinsic motivation of the students for learning the new knowledge. The flexible use of the life examples in the class teaching can motivate the learning positivity of the students and enforce the cognitive level of the students.

2) Enrich the Scientific Concepts of Representation Construction by the Experiments

The biology is a course which attaches the importance to the practices and the experiments are the necessary methods in the biology teaching. Many concepts need to be embodied by the detailed and perceptual experiments. The experiments can help the students search the natural attributes of the things so as to construct the concepts. When the teachers design the teachings, they can arrange some experiments before the teaching contents and let the students achieve the new knowledge through positive exploration. For example, before teaching the contents of the chapter of "Source of Energy: Light and Photosynthesis", the teachers can ask the students to extract and separate the chlorophyll from plant leaves themselves. Through the experiments, the students understand that the adding of $\mathrm{SiO} 2$ can be helpful for the full grinding and $\mathrm{CaCO} 2$ can prevent the pigments from destroying during the grinding, and the students can get to know finally that the layered structures of the pigments are the carotene, chlorophyll, chlorophyll a, chlorophyll b. Comparing to the simply mechanical memorization, such process can be more beneficial for the cognitive development of the students. Meanwhile, the experiments process can not only improve the operational 
ability but also master the experimental principles and the important matters, and the most importantly, it can enable the students get the conclusion through the self-analysis. Besides, the teachers can also organize the students to make the biological models for consolidating the mastered knowledge and constructing the scientific concepts. For example, making the models of "chromosomal changes in meiosis", "structure of eukaryotic cells" and "double coiled spiral structure of DNA" etc. Through the activities of making the models, the knowledge learned can be consolidated, and the operational ability, creative thinking and cooperative ability of the students can be strengthened, and the students' interests of learning the biology can be improved.

\section{E. Strengthen the Exercises of the Thinking Method of the Core Concepts}

1) Consolidating the Understanding of the Concepts by Applying the Variable Exercises

The variant is a teaching mode that catches the natural attributes of the things through changing the non-natural attributes such as representation forms, conditions and situations etc. For example, after learning the meiosis, the students can't understand fully many concepts. At this time, the teachers need to provide some variable exercises for the students. This is an effective strategy of helping the students understand gradually, master and apply the concepts. Before the students construct the complete knowledge background and they can't connect well all of the knowledge learned, the teachers should design the accordingly variable exercises according to the relevant contents and break the meanings of the concepts so as to promote the generation and the construction of the concepts.

\section{2) Acquire a Better Understanding of the Core Concepts} by the Actual Practices

As the theory of "cone of experience", the teachers should let the students get more direct experiences and avoid too many indirect experiences and prevent the preach of "concept to concept" [4]. As the materialistic dialectics, we need to view the things with a related, developing and contradictory perspective. The concepts of the biology are also the same as for sure. The operation by hand and the practices are one of the important routes of evaluating the understanding level of the students for the core concepts. For example, when teach the contents of the chapter of "inorganic substances in cells", the teachers let the students use the test tubes containing the dry seeds of rice to be baked under the alcohol lamp, then the students can see the drops of water on the inner wall of the test tubes for experiencing the existence of the bound moisture, by this way, the understanding and memorization of the students for the bound moisture will be enforced.

\section{SUMMARY}

Building the core concepts strategy fitting for the law of cognitive development of the students and promoting the building of the core concepts of the students are one of the important methods of improving the scientific literacy of the students. The teachers must read up the textbooks, refine and identify the core concept and clarify the key contents of the class teaching. The teachers should use the richly detailed examples to analyze the core concepts with the multiple perspectives, and let the students search the factual support for the core concepts and master correctly the intention and extension of the core concepts. Then, the teachers should instruct the students to bind the core concepts with the general concepts and the detailed concepts, and search the logic supports for the core concepts by making the concept map. Finally, the students need to strengthen the exercises of the thinking methods for the core concepts and apply the knowledge learned for understanding and mastering more well the core concepts. There are many other methods for promoting the building of the core concepts of the biology. These methods need the long-term researches and explorations of the teachers, and these methods need more the examinations in the teaching practices.

\section{REFERENCES}

[1] J.H. Zhou, "Study on the construction of core concepts for teaching in junior high school,” Modern Primary and Secondary Education, vol. 3, pp. 83-85, 2016. (In Chinese)

[2] C.J. Wu, "Thinking into the Transferring ,Forming and Changing of the Concepts in the Biology Textbooks of Senior High Schools," Curriculum, Teaching Material and Method, vol. 4, pp. 66-73, 2012. (In Chinese)

[3] X.Y. Kang, "The inheritance of connotation - denotation in Chinese Shuangguan,” Foreign Language Research, vol. 2, pp. 36-41, 2015. (In Chinese)

[4] Y.F. Zhang, and Y.Y. Guo, "Some thoughts on constructing physics concepts based on subject core concepts," Curriculum, Teaching Material and Method, vol. 5, pp. 99-102, 2015. (In Chinese)

[5] F.K. Liu, and W.J. Wang, "The Effective Application of concept map to teaching and learning: A Case Study,” Journal of Distance Education, vol.3, pp. 59-62, 2009. (In Chinese)

[6] L.H. Ye, "The cone of experience theory and its practical implications," E-education Research, vol. 2, pp. 20-24, 1997. (In Chinese) 